\title{
A BASE NACIONAL COMUM CURRICULAR (BNCC) PARA EDUCAÇÃO INFANTIL
}

\author{
Antônia Avanildes Cardozo ${ }^{1}$ \\ Adriana Aparecida da Cruz Alves ${ }^{2}$ \\ Carina da Silveira Campos 3 \\ Eliane Maria de Lima Paixão ${ }^{4}$ \\ Gleice Aparecida Martins ${ }^{5}$ \\ Raiza Mara Aparecida de Almeida ${ }^{6}$ \\ Silvia Casmal de Freitas ${ }^{7}$
}

RESUMO: Este artigo analisa os desenvolvimentos da Base Curricular Comum Nacional (BNCC) para a educação infantil e destaca os avanços e retrocessos dessa base. Conclui-se que o documento é ambíguo porque, embora represente avanços na educação infantil, principalmente no que se refere ao conceito de infância e organização curricular, apresenta retrocessos em seus desdobramentos para a prática pedagógica e por si só como documento normativo característico que limita a autonomia de professores e crianças na elaboração de currículos.

Palavras-chave: Base Nacional Comum Curricular. Educação Infantil. Currículo.

ABSTRACT: This article analyzes the developments of the National Common Curriculum Base (BNCC) for early childhood education and highlights the advances and setbacks of this base. It is concluded that the document is ambiguous because, although it represents advances in early childhood education, especially with regard to the concept of childhood and curricular organization, it presents setbacks in its consequences for pedagogical practice and by itself as a characteristic normative document that limits the autonomy of teachers and children in the development of curricula.

Keywords: Common National Curriculum Base. Child education. Resume.

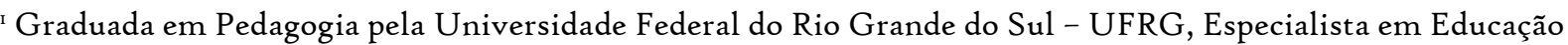
Ambiental pelas Faculdades Integradas Mato-Grossenses de Ciências Sociais e Humanas - ICE.

2 Graduada em Pedagogia pela Universidade de Cuiabá - UNIC. Especialista em Educação Infantil e Alfabetização pela Faculdade Poliensino - FP.

3 Graduada em Pedagogia pela Universidade Federal de Mato Grosso - UFMT.

${ }^{4}$ Graduada em Pedagogia pelas Faculdades Integradas Mato-Grossenses de Ciências Sociais e Humanas ICE, Especialista em Educação Infantil e Alfabetização pelas Faculdades Integradas Mato-Grossenses de Ciências Sociais e Humanas - ICE.

${ }_{5}^{5}$ Graduada em Pedagogia pela Universidade de Cuiabá - UNIC. Especialista em Psicopedagogia Institucional pela Faculdade São Luíz.

${ }^{6}$ Graduada em Pedagogia pela Universidade de Cuiabá - UNIC, Especialista em Neuropsicopedagogia pelo Instituto de Ensino Superior de Minas Gerais - IESMIG.

${ }^{7}$ Graduada em Pedagogia pela Universidade de Cuiabá - UNIC. Especialista em Educação Infantil com Ênfase em Alfabetização pela Faculdade INVEST de Ciências e Tecnologia.
} 


\section{INTRODUÇÃO}

A Base Curricular Comum Nacional (BNCC) continua sendo um documento polêmico, objeto de várias críticas e longe de fazer parte do cotidiano da educação básica brasileira. Entre os vários pontos polêmicos do documento, destaca-se a intenção de criar uma unidade curricular para contextos educativos plurais e diversificados, que se caracterizam pela complexidade e pelas inúmeras diferenças socioculturais, políticas e econômicas, através de orientações de externalização.

Sem negar a importância de diretrizes mais gerais, que, ao lado de outros elementos centrais da ação pedagógica, oferecem suporte teórico e epistemológico para pensar a concepção de educação, infância, currículo e avaliação, o BNCC é muito prescritivo e deixa pouco espaço para os professores e os alunos decidem as práticas curriculares em que estão inseridos.

\section{DESENVOLVIMENTO}

2.I Educação Infantil e BNCC

Reconhecemos as diferentes formas de linguagens e currículos infantis que valorizam a produção de sentidos pelas crianças, frente a uma visão escolar da Educação Infantil, que privilegia e valoriza um determinado tipo de linguagem, em detrimento da pluralidade de formas de expressão e produção cultural.

Em 2017, foi apresentada a terceira e última versão da Base Nacional Comum Curricular para a Educação Infantil e Primária. Este documento tem como objetivo orientar as práticas curriculares na educação básica em todo o território nacional, a fim de reduzir as desigualdades na educação das crianças e determinar o que deve ser ensinado em seus processos escolares (BRASIL, 2017).

Documentos anteriores, como RCNEI e DCNEI, forneceram diretrizes e diretrizes para o desenvolvimento do currículo escolar. Com o BNCC, porém, o caráter diretivo e conteúdo do currículo tem se acentuado, deixando pouco espaço para as instituições e disciplinas neles presentes, especialmente crianças e professores, expressarem sua paternidade e produção cultural nas práticas curriculares. 
No caso específico da educação infantil, percebemos ambigüidades na versão final do documento. Embora a base avance no conceito de infância e supere o olhar passivo das crianças em seus processos educativos e de socialização, por outro lado em seus desdobramentos para a prática educativa, o documento é apresentado de forma bastante prescritiva, com base em modelos universais de desenvolvimento, comparada à perspectiva da criança como sujeito histórico e social.

Mello et al. (2016) analisou a segunda versão da Base e identificou avanços quanto aos documentos que a antecederam, especificamente, concepção de criança, organização curricular, corpo/movimento e brincadeira/jogo. No que se refere ao conceito de infância, a visão presente no BNCC, que já existia nas DCNEI, migra de pressupostos ancorados na Psicologia Evolutiva, especialmente nas matrizes piagetiana e evolutiva, de caráter maturativo e universal, para uma perspectiva baseada na psicologia evolutiva. . Sociologia da infância, na qual a criança é vista como sujeito ativo e autoritário em seus próprios processos de socialização e desenvolvimento.

Em termos de organização curricular, enquanto o RCNEI se centra na ideia de eixos de aprendizagem e DCNEI em diferentes línguas, o BNCC valoriza os campos de vivência das crianças, cujo enfoque passa do aprendiz para o aprendiz, ou seja,. É interessante entender o que as crianças fazem, por meio de suas vivências, com o aprendizado que lhes é oferecido. Essas aprendizagens ocorrem com diferentes linguagens, portanto, não se exclui, mas incorpora a ideia contida no DCNEI.

Nesse sentido, a organização curricular, nesta terceira versão do BNCC, traz alguns pontos que são objeto de análise, como a subdivisão da Educação Infantil em três faixas etárias: recém-nascidos (de o a I8 meses); crianças muito pequenas (I9 meses a 3 anos e II meses) e crianças ( 4 anos a 5 anos e II meses), bem como desenho pedagógico baseado em campos de experiência e objetivos de aprendizagem e desenvolvimento. No entanto, alguns estudos levam a um debate sobre a existência ou não de consenso sobre os avanços na organização curricular do BNCC na educação infantil.

A temática da divisão da Educação Infantil por faixa etária tem gerado discussões sobre essa separação, traçando a psicologia do comportamento, sendo que a crítica que recai sobre o desenvolvimento da criança é classificada em estágios de desenvolvimento 
(ARELARO, 2017). No entanto, o texto da BNCC considera que essa divisão foi necessária para considerar as especificidades de cada faixa etária e pondera que esses grupos etários não devem ser "considerados de forma rígida, já que há diferenças de ritmo na aprendizagem e no desenvolvimento das crianças que precisam ser consideradas na prática pedagógica" (BRASIL, 2017, p. 46).

Em relação à organização curricular, a partir dos campos de experiência, Buss-Simão (2016) destaca que para garantir que as práticas pedagógicas abarquem e possibilitem experiências educativas é necessário que haja a superação da concepção de criança e de corpo como natureza. Conceber esses dois fatores como natureza é homogeneizar as ações dos sujeitos e desconsiderar a influência de outras esferas como a cultura, a sociedade e o momento histórico, por exemplo. Para a autora, "o ser humano deve ser considerado em sua inteireza biocultural [...], dito de outra forma, no ser humano, o biológico encontra-se constituído pela cultura" (BUSS-SIMÃO, 2016, p. 187).

De forma que esses aspectos determinam o modo de vida e a formação do corpo, que ocorrem no entrelaçamento da natureza e da cultura. Assim, segundo a autora, para hospedar e possibilitar experiências educacionais nesse sentido, o planejamento deve incluir indissociavelmente os campos de vivência propostos pelo BNCC, que levem em conta o saber cotidiano na educação infantil, ou seja, a transferência de medidas disciplinares e desinteresse pela cultura infantil.

No que concerne os direitos de aprendizagem e desenvolvimento, Aquino e Menezes (2016) afirmam que a BNCC ao constituir os objetivos educacionais e transformá-los em objetivos de aprendizagem e desenvolvimento, deslocam o foco do sujeito direcionando para "uma educação que prepara sujeitos para a vida e para a cidadania pré-estabelecidas em detrimento da educação que potencializa a vida e a participação dos sujeitos na realidade concreta" (AQUINO; MENEZES, 2016, p. 32).

Por outro lado, o BNCC, em seu texto, apresenta os objetivos de aprendizagem e desenvolvimento como conhecimentos essenciais relacionados aos campos de experiência, correspondendo às possibilidades de aprendizagem e às características de desenvolvimento das crianças. Por meio desses objetivos, as crianças podem ter um papel ativo na 
consolidação de seus direitos de aprendizagem e desenvolvimento no cotidiano da educação infantil.

Ao considerar os campos de vivência na organização curricular, a aprendizagem deve estar voltada para a criança, suas vivências e contextos, favorecendo um olhar sensível e ouvindo os saberes oferecidos. Dessa forma, ao colocar o currículo nos espaços de vivência das crianças, a forma de ver o currículo e seu conteúdo é modificada, proporcionando um movimento dinâmico de pensamento, interpretação e criação, justificando a importância da permanência do termo campos na experiência no BNCC.

Contudo, apesar da potência dos campos de experiências, a institucionalização e a sistematização da experiência em campos temáticos pode afetar a própria potência desse "fenômeno", pois a experiência não é dada a priori, mas, ao contrário, ela emerge da imprevisibilidade do cotidiano e na criatividade/inventividade dos sujeitos que dele fazem parte (MELLO et al., 2016, p. 137).

No que diz respeito ao corpo/movimento, o RCNEI apresenta uma perspectiva instrumental no sentido de que entende o corpo e o movimento como meios de aquisição de determinados conhecimentos. As RCNEIs vêem o corpo/movimento como linguagem, como uma forma de expressão para as crianças. Por outro lado, partindo da ideia da criança como sujeito que pensa e age sobre si mesmo, entende o corpo/movimento como dimensões do comportamento que estão relacionadas à construção de significados pelas crianças. Por fim, o RCNEI aborda os jogos e brincadeiras como estratégias metodológicas de ensino, o DCNEI como objetos de aprendizagem, como capital da cultura lúdica infantil. A Base, por sua vez, trata os jogos e brincadeiras como um direito de aprendizagem das crianças na educação infantil.

Os direitos da criança estão consubstanciados nos direitos de aprendizagem e desenvolvimento, com base nos seis verbos presentes na última versão do BNCC. De acordo com o documento, as instituições de educação infantil, para proporcionar uma aprendizagem efetiva às crianças, devem proporcionar-lhes tempo e espaço para se socializar, brincar, participar, explorar, se expressar e se conhecer (BRASIL, 2017).

Têm, portanto, o direito de conviver coletivamente e de forma diversificada na escola, exercendo o seu direito ao brincar, fundamental para que todos possam conviver e aprender a brincar. Porém, esse direito está atrelado à escolha didático-pedagógica do 
professor, com o desenvolvimento de planos de estudos e projetos pedagógicos, considerando as especificidades de cada criança em seu contexto social, justificando a parte diversificada do BNCC.

Marques, Pegoraro e Silva (2018) ressaltam que as versões do BNCC se basearam nas ideias político-didático-pedagógicas do DCNEI, com foco na formação integral das crianças, cujo protagonismo e suas vivências foram reconhecidos, o foco de aprendizagem dos conteúdos se deslocou e assim diferenciado de RCNEI. Ao abordar questões que afetam o cotidiano escolar, a terceira versão do BNCC percebe avanços, como a visão da educação integral, por meio de um aprendizado mais ativo, mais prático e menos apresentado. Do lado político, as crianças agiriam democraticamente se participassem de diferentes grupos e expressassem suas opiniões e desejos. E quanto ao aspecto estético, as crianças exercitariam esse direito ao explorar o mundo e inventar seus jogos.

Apesar dos avanços, os desdobramentos da versão final da Base (BRASIL, 2017) para as práticas pedagógicas expuseram um texto enxuto sobre a primeira etapa da Educação Básica, que trata o percurso de ensino e aprendizagem e a aquisição do conhecimento de modo instrumental (BARBOSA et al., 2019).

Gonçalves e Peixoto (2016) indicam que a BNCC é um documento que visa universalizar e apontar conhecimentos e práticas iguais para todos, com uma perspectiva de currículo que consolida a linearidade dos processos de aprendizagem. Assim, encaminhamentos prescritivos, externamente impostos, tais como parâmetros estabelecidos pelos direitos de aprendizagem e desenvolvimento para bebês, crianças bem pequenas e crianças pequenas, envolvem um modelo de como ensinar, com descrição engessada de habilidades a serem desenvolvidas.

A terceira e última versão da BNCC, em análise neste texto, se difere das edições que a antecederam e que foram marcadas pela dinâmica participativa e coletiva de sua formulação. Em sentido contrário, a versão final da Base incorporou, no apagar das luzes, pressupostos de natureza didáticometodológica propostos por grupos e instituições privadas de educação (Fundação Lemann, Instituto Ayrton Senna, Movimento Todos pela Educação, entre outros). 
Essa formulação, ao se apresentar de maneira bastante prescritiva quanto aos conteúdos, formas de ensinar, quando ensinar e avaliar, acabou engessando as produções curriculares dos praticantes dos cotidianos e, em grande medida, se contrapondo aos referenciais epistemológicos e teóricos que sustentam a BNCC na Educação Infantil.

Desse modo, a BNCC se apresenta como aliada na efetivação de propostas e dinâmicas curriculares que contribuem para a padronização e reducionismo curricular, com forte ênfase em Língua Portuguesa e Matemática, profundamente articulada à avaliação estandardizada, desconsiderando a realidade nacional, as diretrizes curriculares nacionais dos níveis da Educação Básica e as singularidades das etapas e modalidades educativas (DOURADO \& OLIVEIRA, 20I8, p. 4I).

Uma das principais críticas à versão final da base, no capítulo da educação infantil, centra-se na ênfase nos processos de leitura e escrita, principalmente orientados para a leitura e a escrita. Essa ênfase antecipa modelos de escola que existem em estágios posteriores que negligenciam ou reduzem significativamente outras experiências e experiências relacionadas às cem linguagens (e cem mais) das crianças.

Sem desconsiderar a importância da linguagem sistematizada através da leitura e da escrita, linguagem que materializa as formas escolares, entendemos que a internalização e o desenvolvimento desta linguagem não deve ser desvinculada das outras linguagens, nem deve assumir tal predominância a ponto de hierarquizar . entre diferentes conhecimentos.

Tizuko Khishimoto (2003) citando Paulo Freire, diz que a leitura de mundo antecede a leitura da palavra. O desenvolvimento de outras linguagens, que potencializem a apropriação e experimentação do mundo, são fundamentais para o desenvolvimento integral das crianças. Antes de sistematizar a realidade pelos códigos e signos dados pela linguagem verbal articulada, é preciso vivenciá-la e experimentá-la, para que essa sistematização não se torne letra morta, ou seja, uma linguagem destituída de sentidos pelos seus enunciantes.

$\mathrm{Na}$ perspectiva da articulação entre diferentes linguagens, o brincar, direito inalienável da criança, não deve ser visto como contraditório na aprendizagem para não reforçar a dicotomia entre corpo e mente, como se o corpo da criança fosse o outro da razão. O risco aqui reside na ênfase em processos de ensino diretivos em que a criança é vista apenas como um aluno. A infância, por sua vez, é o resquício de um tempo decorrido, para que no restante as crianças aprendam primeiro, cumpram sua missão institucional e brinquem (SIROTA, 200I). 
Atua como uma linguagem típica da infância que precisa estar presente nas diferentes experiências de aprendizagem e nas relações que constroem com os diversos saberes. Por meio de suas experiências lúdicas, as crianças internalizam e produzem culturas, tornam-se agentes de si mesmas e autores de suas próprias vidas. Portanto, entendemos que a ênfase nos processos de alfabetização não deve reter as crianças na infância para antecipar as futuras demandas escolares.

Assim, os estudos na área de Educação Física enfatizam as vivências das crianças com ênfase no seu protagonismo e nas suas práticas lúdicas, e revelam conhecimentos que se constituem nas experiências que as crianças adquirem com as atividades lúdicas e com os pares que precisam ser consideradas organizações curriculares desde cedo nas instituições de educação infantil (SAYÃO, I999; GASPAR; RICHTER; VAZ, 2015; BARBOSA, MARTINS; MELLO, 2017).

Além do impacto nas crianças, as propostas curriculares de orientação externa que ditam práticas pedagógicas aos professores privam os professores de autonomia profissional, permitindo-lhes reproduzir mecanicamente conhecimentos inventados por terceiros e pouco dialogar com as exigências da sua cultura escolar específica. Nesse caso, os professores não são vistos como criadores de suas próprias práticas, mas sim como reprodutores de um conhecimento universalmente estabelecido.

\section{CONCLUSÕES}

A BNCC não anula os documentos anteriores (RCNEI e DCNEI), mas sugere um conjunto de orientações para a construção curricular, bem como o facto de a terceira versão do BNCC abordar os eixos estruturais de interação e jogo, as áreas de vivência e aprendizagem e objetivos que permite um enfoque no trabalho educativo e lúdico com as crianças.

Embora não haja consenso sobre os avanços na educação infantil por parte do BNCC, principalmente na produção acadêmica, apontamos a necessidade de garantir experiências diversificadas para, com e entre as crianças para o aprimoramento de suas linguagens.

A base, portanto, limita as consequências dos currículos para a prática pedagógica ao mesmo tempo, ao incluir avanços teórico-conceituais em relação à infância e à organização 
curricular da educação infantil, e se caracteriza como um documento dado. Comparado aos demais níveis da educação básica, o documento da educação infantil é ainda mais flexível e menos indicativo, uma vez que esse nível não é voltado para conteúdos disciplinares.

A abertura do BNCC a uma parte diversificada do currículo, que leve em conta as diferenças locais, a direção do trabalho e a forma de trabalhar em cada fase da educação infantil e pré-escolar, acarreta uma restrição na produção curricular dos praticantes do cotidiano. e, em muitos aspectos, se opõem a estabelecer um conceito de infância e desenho curricular centrado nas experiências das crianças nas quais o documento se baseia.

Em muitos padrões de prática pedagógica mencionam perspectivas maduras e universais sobre o desenvolvimento infantil com base em taxonomias que não levam em consideração as dimensões socioculturais e contextuais desse desenvolvimento. Sem negligenciar a importância dos aspectos biológicos no processo de desenvolvimento da criança, negligenciar as influências de outras dimensões visa reforçar a dicotomia entre natureza e cultura que várias áreas do conhecimento procuram superar, incluindo o próprio BNCC em seus alicerces.

No entanto, não podemos deixar de afirmar que o documento não prescinde de uma secção variada que corresponde às especificidades de cada região, escola e contexto social. Talvez seja uma forma de dar ao currículo diferentes interpretações, práticas e adaptações às circunstâncias locais.

Por fim, não se deve ignorar a perda do caráter participativo e democrático da versão final do BNCC. Se na primeira e na segunda versão confere ao documento certa representatividade e legitimidade com a participação de diferentes setores da sociedade civil organizada, então na terceira e última versão as interpretações negativas geradas por setores e grupos educacionais privados na formulação final do documento, questionando as intenções por trás desta ação.

\section{REFERÊNCIAS}

AQUINO, Ligia Maria Motta Leão de; MENEZES, Flávia Maria de. Base Nacional Comum Curricular: tramas e enredos para a infância brasileira. Debates em Educação, v. 8, n. I6, p. 29-45, jul./dez. 2016. 
ARELARO, Lisete Regina Gomes. Avaliação das políticas de educação infantil no Brasil: avanços e retrocessos. Revista Zero-a-seis, v. 19, n. 36, p. 206-222, jul./dez. 2017. ARELARO, Lisete Regina Gomes. Resistência e Submissão: a reforma educacional na década de i99o. In: KRAWCZYK, Nora; CAMPOS, Maria Malta; HADDAD, Sérgio (Org.). O cenário educacional latinoamericano no limiar do século XXI: reformas em debate. Campinas/SP: Autores Associados, 2000. p. 95-116.

BARBOSA, Ivone Garcia et al. A BNCC e a Regulação da Educação Infantil: Perspectiva Critica. CONAPE 2018.

BARBOSA, Maria Carmen Silveira. A BNCC e os direitos das crianças: Educação Infantil em evidência. Revista Com Censo: estudos educacionais do Distrito Federal, Brasília, v. 5, n. 2, p. 9-13, maio, 2018.

BARBOSA, Raquel Firmino Magalhães; MARTINS, Rodrigo Lema Del Rio; MELLO, André da Silva. Brincadeiras lúdico-agressivas: Tensões e possibilidades no cotidiano na Educação Infantil. Movimento, Porto Alegre, p. 159-170, mar. 2017.

BRASIL. Ministério da Educação. Secretaria de Educação Básica. Base Nacional Comum Curricular. Brasília, DF: MEC/SEB, 2017.

BRASIL. Referencial Curricular Nacional para a Educação infantil. Brasília: MEC/ SEF, 1998.

BRASIL. Ministério da Educação. Conselho Nacional de Educação. Diretrizes Curriculares Nacionais para a Educação infantil. Brasília/DF, 2009.

DOURADO, Luiz Fernandes; OLIVEIRA, João Ferreira de. Base Nacional Comum Curricular (BNCC) e os impactos nas políticas de regulação e avaliação da educação superior. In: AGUIAR, Márcia Angela da Silva; DOURADO, Luiz Fernandes (org.). A BNCC na contramão do PNE 2014-2024: avaliações e perspectivas. Recife: Biblioteca ANPAE, 2018. p. 38-43.

GASPAR, Bárbara dos Santos; RICHTER, Ana Cristina; VAZ, Alexandre Fernandez. Das práticas pedagógicas para a educação física infantil de o a 3 anos no município de Florianópolis. Currículo sem Fronteiras, v. 15, n. I, p. 231-25I, jan./abr. 2015.

GONÇALVES, Rafael Marques; PEIXOTO, Leonardo Ferreira. Em defesa dos currículos praticados pensados nos cotidianos escolares. In: REUNIÃO CIENTÍFICA ANPED 
NORTE, I., 2016, Belém. Anais. Belém: Anped, 2016, p. 2009-2021. Disponível em: http://ppgedufpa.com.br. Acesso em 06/1I/2021.

MARQUES, Circe Mara; PEGORARO, Ludimar; DA SILVA, Ezequiel Theodoro. Do assistencialismo à Base Nacional Comum Curricular (BNCC): movimentos legais e políticos na Educação Infantil. Revista Linhas, Florianópolis, v. 20, n. 42, p. 255-28o, jan./abr. 2019.

SAYÃO, Deborah Thomé. Educação Física na Educação infantil: riscos, conflitos e controvérsias. Motrivivência, Florianópolis, n. 13, p. 221-238, nov. 1999.

SIROTA, Régine. Emergência de uma nova sociologia da infância: evolução do objeto e do olhar. Cadernos de Pesquisa, São Paulo, n. II2, p. 7-31, mar. 2001. Movimento-Revista de Educação, Niterói, ano 6, n.ı, p. 147-172, jan./jun. 2019. 